\title{
Microbiological Quality of Ready-to-Eat Vegetables Collected in Mexico City: Occurrence of Aerobic-Mesophilic Bacteria, Fecal Coliforms, and Potentially Pathogenic Nontuberculous Mycobacteria
}

\author{
Jorge Francisco Cerna-Cortes, ${ }^{1}$ Nancy Leon-Montes, ${ }^{1}$ \\ Ana Laura Cortes-Cueto, ${ }^{1}$ Laura P. Salas-Rangel, ${ }^{1}$ Addy Cecilia Helguera-Repetto, ${ }^{2}$ \\ Daniel Lopez-Hernandez, ${ }^{3}$ Sandra Rivera-Gutierrez, ${ }^{1}$ \\ Elizabeth Fernandez-Rendon, ${ }^{1}$ and Jorge Alberto Gonzalez-y-Merchand ${ }^{1}$ \\ ${ }^{1}$ Departamento de Microbiologia, Escuela Nacional de Ciencias Biologicas-Instituto Politecnico Nacional, \\ Prolongacion Carpio y Plan de Ayala S/N, Colonia Casco de Santo Tomas, Delegacion Miguel Hidalgo, 11340 Mexico, DF, Mexico \\ ${ }^{2}$ Departamento de Inmunobioquimica, Torre de Investigación, Instituto Nacional de Perinatología Isidro Espinosa de los Reyes (INPer), \\ Montes Urales 800, Colonia Lomas de Virreyes, 11000 Mexico, DF, Mexico \\ ${ }^{3}$ Departamento de Epidemiologia y Bioestadistica, Centro de Investigación y de Educación Continua (CENINVEC), Oyameles 30, \\ Colonia La Perla, 57820 Ciudad Nezahualcóyotl, MEX, Mexico
}

Correspondence should be addressed to Jorge Alberto Gonzalez-y-Merchand; jgonzal1212@yahoo.com.mx

Received 22 August 2014; Accepted 24 September 2014

Academic Editor: Petr Kralik

Copyright (C) 2015 Jorge Francisco Cerna-Cortes et al. This is an open access article distributed under the Creative Commons Attribution License, which permits unrestricted use, distribution, and reproduction in any medium, provided the original work is properly cited.

\begin{abstract}
The aims of this study were to evaluate the microbiological quality and the occurrence of nontuberculous mycobacteria (NTM) in a variety of salads and sprouts from supermarkets and street vendors in Mexico City. Aerobic-mesophilic bacteria (AMB) were present in $100 \%$ of RTE-salads samples; $59 \%$ of samples were outside guidelines range ( $>5.17 \log _{10}$ CFU per g). Although fecal coliforms (FC) were present in $32 \%$ of samples, only $8 \%$ of them exceeded the permissible limit (100 MPN/g). Regarding the 100 RTE-sprouts, all samples were also positive for AMB and total coliforms (TC) and 69\% for FC. Seven NTM species were recovered from 7 salad samples; they included three $M$. fortuitum, two $M$. chelonae, one M. mucogenicum, and one $M$. sp. Twelve RTE-sprouts samples harbored NTM, which were identified as M. porcinum (five), M. abscessus (two), M. gordonae (two), M. mucogenicum (two), and M. avium complex (one). Most RTE-salads and RTE-sprouts had unsatisfactory microbiological quality and some harbored NTM associated with illness. No correlation between the presence of coliforms and NTM was found. Overall, these results suggest that RTE-salads and RTE-sprouts might function as vehicles for NTM transmission in humans; hence, proper handling and treatment before consumption of such products might be recommendable.
\end{abstract}

\section{Introduction}

According to the definition given by the FAO and the WHO [1], ready-to-eat (RTE) foods include any comestible that is normally consumed in its raw state. Demand for RTE food has led to an increase in the amount and selection of different products available for the consumers [2]. RTE-salads and RTE-sprouts constitute a suitable and convenient meal for today's lifestyles because they need no cooking or further preparation. As well as being considered low-calorie food, they are rich in fiber and provide a great variety of vitamins, minerals, and other phytochemicals [3]. Their consumption is encouraged in many countries by government health agencies to protect people against a range of illnesses such as cancer and cardiovascular diseases [4]. Therefore, continued increase in the consumption of fresh meals has occurred 


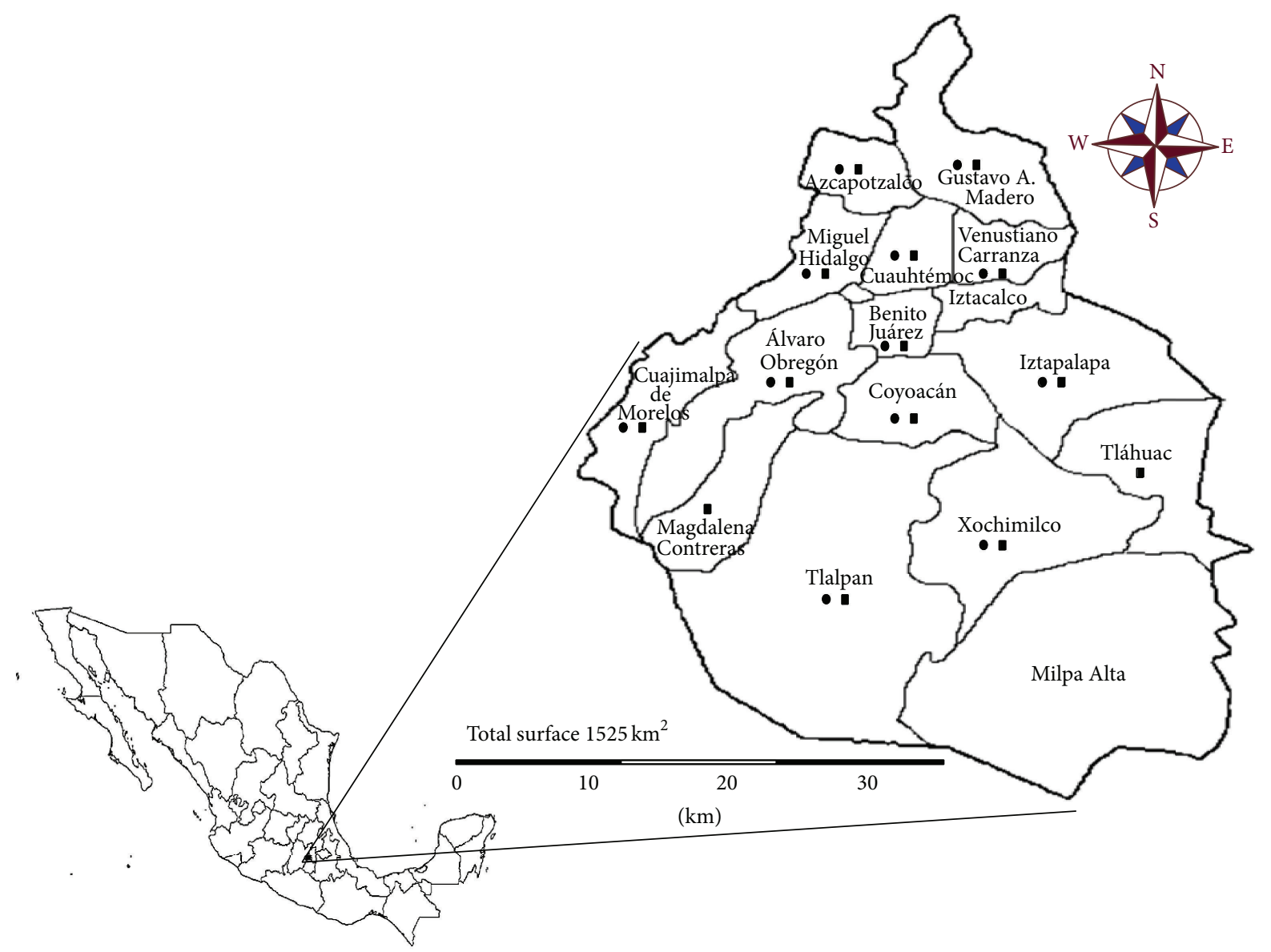

FIgURE 1: Boroughs of Mexico City where RTE-salads (•) and RTE-sprouts ( $\mathbf{\bullet})$ were collected.

as a result of efforts to promote better nutrition in the population [4]. As RTE-salads and RTE-sprouts do not need further preparation before consumption, they could potentially contain pathogens that form part of their microflora, posing a public health problem. Fresh vegetables can become contaminated by pathogens as Salmonella at any point during the food production process. During preharvest, contact with contaminated irrigation water, soil, manure, or fecal matter of wild animals may occur. These pathogens can both bind to plant leaves and/or be internalized via the leaves or the endophytic root system $[5,6]$. During harvest, asymptomatic human carriers might contaminate the products, and at the postharvest level, products become contaminated by contact with polluted water, other asymptomatic human carriers, or the production process environment. Over the last 30 years there has been at least a $24 \%$ of increase in the average amount of fresh vegetable consumed per person in the USA [7]. Moreover, the number of gastroenteritis outbreaks caused by foodborne pathogens after consumption of raw vegetables salads and sprouts has increased worldwide [8-11]. Even though Salmonella is the most common cause of disease outbreaks associated with lettuce and sprouts [12-15], there are other pathogens (Shiga toxin, producing E. coli O157, Norovirus) that have been described as relevant microbial hazards [16-18]. For example, a large outbreak of hemolyticuremic syndrome caused by STEC O104:H4 linked to sprouts occurred in Germany $[19,20]$.

Nontuberculous mycobacteria (NTM) are opportunistic pathogens found in the environment that cause lifethreatening infections in humans, other mammals, and birds $[21,22]$. The incidence of NTM disease is increasing worldwide [23], in both immunocompetent and immunocompromised subjects $[22,24,25]$. As there is no defining evidence for person-to-person transmission for most of the NTM $[24,25]$, it is therefore important to establish the sources and routes of NTM transmission, since infections can occur through inhalation, ingestion, gastric reflux, or skin trauma $[22,26]$. NTM have been isolated from various kinds of food, and many studies support the hypothesis that food, especially raw or partially cooked products, plays a role as a source of NTM for humans, primarily in countries with similar processing food routes and climates [27-29]. The aims of this study were to evaluate the microbiological quality of RTE-salads and RTE-sprouts collected in Mexico City and to analyze the occurrence of NTM in these samples, in order to determine whether these RTE foods may represent a potential risk for NTM infection for the consumers. 


\section{Material and Methods}

2.1. Area of Study and RTE Food Collection. The selected area of study was Mexico City, a large urban area that, although it has almost 9 million registered inhabitants, during working hours, reaches a population of nearly 25 million. Mexico City is divided into 16 "delegaciones" or boroughs (Figure 1). From January to July 2013 a total of 100 RTE-salads samples of raw vegetables (salads from SPM contained mainly lettuce and spinach accompanied by carrot and purple cabbage, while salads from SVS also contained onion, tomatoes, cucumber, Mexican turnip, mushroom, radish, coriander, cactus, and fruits as strawberry, apple, and mango) were collected from different boroughs (Figure 1): 50 samples from different supermarkets (SPM) and 50 from street-vendor stalls (SVS). Also, 100 RTE-sprouts samples (alfalfa, soybean, broccoli, carrot, radish, onion, amaranth, clover, arugula, lentil, wheat, melon, turnip or combinations of alfalfa and broccoli, alfalfa and clover, alfalfa and onion, alfalfa and soybean, and alfalfa and radish) were purchased (Figure 1), from August 2013 to February 2014: 50 from different SPM and 50 from SVS. Salads and sprouts collected from SPM were purchased in bags provided by a bigger food processing company. Those vegetables collected from SVS were prepared directly by vendors at the selling spot. At the moment of purchase the RTE-salads and RTE-sprouts were packaged in sterile plastic containers and were transported to the laboratory for their analysis within $2 \mathrm{~h}$ after collection.

2.2. Microbiological Analysis. According to the FDA [30], 50 grams from each sample was placed in ethylene oxide gas-sterilized polypropylene bags (Whirl-Pak, Nasco, USA) and $450 \mathrm{~mL}$ of lactose broth was added in order to achieve a final dilution 1:10 $\left(10^{-1}\right)$. Samples were homogenized for $2 \mathrm{~min}$ in a stomacher (tissue disrupter) and serially diluted $\left(10^{-1}\right.$ to $\left.10^{-5}\right)$; then, these dilutions were used for quantification $(\mathrm{CFU} / \mathrm{mL})$ and estimation $(\mathrm{MPN} / \mathrm{g})$ of microorganisms. Each sample was tested for the presence of aerobic-mesophilic bacteria (AMB), total coliforms (TC), and fecal coliforms (FC) following the methods approved by the FDA's Bacteriological Analytical Manual [30]. All the data obtained in this work was analyzed according to the official 093 guideline [31], which establishes that food samples should only contain up to $5.17 \log _{10} \mathrm{CFU}$ per $\mathrm{g}(150,000 \mathrm{CFU} / \mathrm{g})$ of $\mathrm{AMB}$ and up to $100 \mathrm{MPN} / \mathrm{g}$ of FC.

2.3. Isolation and Identification of Mycobacteria. For both RTE foods (salads and sprouts), $45 \mathrm{~mL}$ of supernatant from dilution $10^{-1}$ was placed in sterile conical centrifugation tubes (Falcon type) of $50 \mathrm{~mL}$ and then was centrifuged $\left(4,000 \times \mathrm{g}\right.$ at $25^{\circ} \mathrm{C}$ for $\left.20 \mathrm{~min}\right)$. Supernatants were discarded, and pellets were resuspended in $20 \mathrm{~mL}$ of $50 \mathrm{ppm}$ chlorine solution or $20 \mathrm{~mL}$ of $0.1 \%$ cetylpyridinium chloride, for salads and sprouts, respectively. The suspensions were incubated at room temperature for $30 \mathrm{~min}$ and then neutralized with $20 \mathrm{~mL}$ of phosphate buffer ( $\mathrm{pH}$ 7.0). Samples were centrifuged as above and pellets were resuspended in $5 \mathrm{~mL}$ of Dubos medium (Difco, Becton Dickinson, Sparks, MD) with albumin-dextrose-catalase (ADC; Becton Dickinson, Mexico); $100 \mu \mathrm{L}$ of this suspension was inoculated onto Middlebrook 7H10 agar (Difco, Becton Dickinson) supplemented with ADC, cycloheximide $(500 \mu \mathrm{g} / \mathrm{mL})$, and the PANTA cocktail (Becton Dickinson) (40 U/mL polymyxin B, $4 \mu \mathrm{g} / \mathrm{mL}$ amphotericin $\mathrm{B}, 16 \mu \mathrm{g} / \mathrm{mL}$ nalidixic acid, $4 \mu \mathrm{g} / \mathrm{mL}$ trimethoprim, and $4 \mu \mathrm{g} / \mathrm{mL}$ azlocillin). Plates were incubated at $35^{\circ} \mathrm{C}$ and were examined daily for the first eight days and thereafter once a week for two months. Once the bacterial growth had been observed on the Middlebrook 7H10 agar, the identification of acid-fast bacilli was carried out by Ziehl-Neelsen stain. Acid-fast bacilli were subcultured on Middlebrook 7H10 agar, labeled by sampling location and with a consecutive number.

Strains belonging to the genus Mycobacterium and to the M. tuberculosis complex were identified by two PCR assays previously described [32]. Briefly, $3 \mu \mathrm{L}$ aliquots of bacterial lysates were subjected to amplification, using a standard Taq polymerase (Life Technologies, Rockville, MD) in a total volume of $50 \mu \mathrm{L}$ of PCR mixture; RAC1 and RAC8 and MTB$\mathrm{F}$ and MTB-R primers [32] were used for identification of the Mycobacterium genus and of the strains belonging to the $M$. tuberculosis complex, respectively. The amplicon produced by the primer combination of RACl and RAC 8 contains the last 99 codons of the murA gene, the promoter region of the $r r n A$ operon, and 360 nucleotides from the $5^{\prime}$ end of the 16S rRNA gene. As shown by Perez-Martinez et al. [33], the amplicon size varies depending on the mycobacteria species, from 934 to $1300 \mathrm{bp}$. MTB-F/MTB-R primers amplified a DNA fragment coding for the last five codons of murA gene, the promoter region of the $r r n A$ operon, and the $5^{\prime}$ end of the $16 \mathrm{~S}$ rRNA; a $488 \mathrm{bp}$ fragment characteristic only for $M$. tuberculosis complex members should be amplified. Therefore, by exclusion, mycobacteria strains that did not belong to the M. tuberculosis complex were considered to be NTM. These NTM species were identified by three methods: (i) PCR restriction enzyme pattern analysis (PRA) of the $65 \mathrm{kDa}$ heat shock protein gene (hsp65), as described by Telenti et al. [34]; (ii) sequencing of the hypervariable region 2 (V2) of the $16 \mathrm{~S}$ rRNA gene [35]; and (iii) sequencing of the rpoB gene [36]. Mycobacterial PRA was performed by PCR amplification of a $439 \mathrm{bp}$ fragment of the hsp65 gene by using primers Tb11 and Tb12 [34]. PCR products were digested in two separate reactions with two restriction enzymes, BstEII (New England Biolabs) and HaeIII (Invitrogen). Digested products were then analyzed using the Agilent 2100 bioanalyzer. DNA 1000 LabChips (Agilent) were used according to manufacturer's protocol. PRA results were interpreted with the algorithm described by Telenti et al. [34], which is available on the PRA database [37].

Identification of the mycobacterial species was also carried out by automatized sequence of the hypervariable region 2 (V2) of the $16 \mathrm{~S}$ rRNA gene and of the rpoB gene. The amplification of the 16S rRNA gene was performed using the $\mathrm{RACl}$ and RAC8 primers [32]. For the amplification of the $r p o \mathrm{~B}$ gene, the Myco-F and Myco-R primers were used to obtain a product of $723 \mathrm{bp}$ [36]. Both products of PCR were sequenced using the RAC8 [32] and Myco-F [36] primers, respectively, and the big dye terminator ready reaction kit 
TABLE 1: Populations and frequencies of aerobic-mesophilic bacteria (AMB), total coliforms (TC), and fecal coliforms (FC) on RTE-salads and RTE-sprouts samples.

\begin{tabular}{|c|c|c|c|c|c|}
\hline Microorganisms group & Minimum & Median & Maximum & Frequency (\%) & $\begin{array}{c}\text { Number of samples out of the } 093 \\
\text { guideline* (\%) }\end{array}$ \\
\hline \multicolumn{6}{|l|}{ RTE-salads from SPM ${ }^{\mathrm{a}}$} \\
\hline $\mathrm{AMB}$ & 3 & 4.9 & 6.6 & $50(100)$ & $21(42)$ \\
\hline $\mathrm{TC}$ & $<3$ & 56 & $>1100$ & $46(92)$ & NA \\
\hline FC & $<3$ & $<3$ & 210 & $7(14)$ & $2(4)$ \\
\hline \multicolumn{6}{|l|}{ RTE-salads from SVS ${ }^{a}$} \\
\hline $\mathrm{AMB}$ & 3 & 6.1 & 6.7 & $50(100)$ & $38(76)$ \\
\hline $\mathrm{TC}$ & 3 & 1100 & $>1100$ & $50(100)$ & NA \\
\hline FC & $<3$ & 1.5 & $>1100$ & $25(50)$ & $6(12)$ \\
\hline \multicolumn{6}{|l|}{ RTE-sprouts from SPM ${ }^{a}$} \\
\hline $\mathrm{AMB}$ & 6.1 & 7.4 & 8 & $50(100)$ & NA \\
\hline $\mathrm{TC}$ & 6.1 & 460 & $>1100$ & $50(100)$ & NA \\
\hline FC & $<3$ & 3.3 & $>1100$ & $29(58)$ & NA \\
\hline \multicolumn{6}{|l|}{ RTE-sprouts from SVS ${ }^{a}$} \\
\hline AMB & 6.1 & 7.3 & 8.8 & $50(100)$ & NA \\
\hline TC & 26 & 1100 & $>1100$ & $50(100)$ & NA \\
\hline FC & $<3$ & 23.5 & $>1100$ & $40(80)$ & NA \\
\hline
\end{tabular}

${ }^{a} n=50$. Minimum, median, and maximum values are in $\log _{10}$ CFU per $g$ for aerobic-mesophilic bacteria and in most probable number (MPN) per $g$ for total coliforms and fecal coliforms. SPM: supermarkets, SVS: street-vendor stalls, and NA: not applicable (there is no official guideline for this food).

${ }^{*}$ Guideline that establishes that food samples should contain up to $5.17 \log _{10}$ CFU per g $(150,000 \mathrm{CFU} / \mathrm{g})$ of AMB and up to $100 \mathrm{MPN} / \mathrm{g}$ of FC.

(Perkin-Elmer, Inc., Wellesley, MA). The sequences were analyzed by ABI PRISM 310 genetic analyzer system (PerkinElmer). Nucleotide sequences were compared to known sequences in the GenBank database by using the Blastn algorithm. Species identifications were based on the $100 \%$ similarity cut-off for the $16 \mathrm{~S}$ rRNA gene and $\geq 97 \%$ for the rpoB gene.

The identification of some of the isolated NTM was not possible using the methods described above; therefore, fulllength 16S rRNA gene was amplified using the 13B/8FPL universal primers [38]. Purified PCR products were directly sequenced in both forward and reverse directions using the same primers as for PCR. Nucleotide sequences were compared to known sequences in the GenBank database by using the Blastn algorithm.

2.4. Statistical Analyses. Categorical variables (AMB, TC, and FC) were compared using the (chi) ${ }^{2}$ test for the 2 categories of origin of samples (SPM and SVS). We calculated $P$ value from Fisher test for corresponding data. The values of median of CFU of AMB and MPN of TC and FC were compared using the Kruskal-Wallis test. Two-tailed probability values were calculated. The point-biserial correlation coefficient $\left(r_{\mathrm{pb}}\right)$ value was calculated to quantify the relationship between the nominal (presence of NTM) and quantitative variables (concentration of AMB, TC, and FC). Similarly, the phi correlation coefficient $\left(r_{\text {phi }}\right)$ value was calculated to quantify the relationship between all nominal variables (presence of NTM and AMB, TC, and FC). A $P$ value $<0.05$ was considered significant. All statistical analysis was run with the Statistical program SPSS for Windows version 21.

\section{Results}

The RTE-salad and RTE-sprout samples had unsatisfactory microbiological quality (results outside acceptable microbiological limits, see reference [39]). A total of 59\% of RTEsalads (21\% from SPM and 38\% from SVS, $P=0.001)$ did not comply with the 093 guideline (see Section 2) (Table 1). In contrast, FC was detected in $32 \%$ of samples; of these, only $8 \%$ exceeded the permissible limit of the official guideline. The median concentration of AMB in RTE-salad samples from SPM was significantly lower than the one observed in those from SVS $(P<0.001)$. Similarly, we found equivalent results when the median concentrations of MPN/g of TC and FC were compared $(P<0.001)$.

AMB and TC were also present in 100\% of RTE-sprouts samples analyzed (Table 1); FC were present in 69\% of samples. The median concentration of FC was significantly lower in RTE-sprouts from SPM (3.3 MPN/g) than the one found in SVS $(23.5 \mathrm{MPN} / \mathrm{g})(P=0.007)$. However, the median concentrations of AMB in samples from SPM and SVS were similar $(P=0.762)$. Likewise, we observed the same result when we compared the median concentration values of TC between samples from SPM and from SVS $(P=0.169)$.

One hundred RTE-salads were tested for the presence of mycobacteria. Seven RTE-salads harbored NTM: three were $M$. fortuitum, two were $M$. chelonae, one was 
TABLE 2: Characteristics of positive samples for NTM and species identified.

\begin{tabular}{|c|c|c|c|c|}
\hline Foods & Origin & $\begin{array}{l}\text { Number of positive } \\
\text { samples, type }\end{array}$ & Ingredients & $\begin{array}{c}\text { Number and species of NTM } \\
\text { identified }\end{array}$ \\
\hline \multirow{3}{*}{ RTE-salads } & SVS & 3, mixed & $\begin{array}{l}\text { Lettuce, carrot, cucumber, } \\
\text { Mexican turnip, } \\
\text { tomatoes, onion }\end{array}$ & $\begin{array}{l}\text { 2, M. fortuitum } \\
1, \text { M. chelonae }\end{array}$ \\
\hline & SVS & 1, mango & $\begin{array}{l}\text { Lettuce, mango, } \\
\text { Mexican turnip, strawberry }\end{array}$ & 1, M. fortuitum \\
\hline & SVS & 3 , nopal & $\begin{array}{l}\text { Cactus, tomatoes } \\
\text { onion, coriander }\end{array}$ & $\begin{array}{c}\text { 1, M. mucogenicum } \\
1, \text { M. chelonae } \\
1, M . s p \\
\end{array}$ \\
\hline \multirow{7}{*}{ RTE-sprouts } & SPM & 3, alfalfa & Alfalfa sprouts & $\begin{array}{l}\text { 2, M. abscessus } \\
\text { 1, M. gordonae }\end{array}$ \\
\hline & SPM & 1, alfalfa and clover & $\begin{array}{l}\text { Alfalfa sprouts } \\
\text { Clover sprouts }\end{array}$ & 1, M. porcinum \\
\hline & SPM & 1, alfalfa and onion & $\begin{array}{l}\text { Alfalfa sprouts } \\
\text { onion sprouts }\end{array}$ & 1, M. porcinum \\
\hline & SVS & 4, alfalfa & Alfalfa sprouts & $\begin{array}{l}\text { 1, M. avium complex } \\
\text { 3, M. porcinum }\end{array}$ \\
\hline & SVS & 1 , alfalfa and soybean & $\begin{array}{l}\text { Alfalfa sprouts } \\
\text { soybean sprouts }\end{array}$ & 1, M. mucogenicum \\
\hline & SVS & 1 , soybean & Soybean sprouts & 1, M. mucogenicum \\
\hline & SVS & 1, broccoli & Broccoli sprouts & 1, M. gordonae \\
\hline
\end{tabular}

SVS: street-vendor stalls; SPM: supermarket.

M. mucogenicum, and one was M. sp (Table 2). All NTM were isolated from RTE-salads collected in SVS $(P<0.05)$. No correlation between the presence of NTM and the presence of $\operatorname{AMB}\left(r_{\text {phi }}=0.154, P=0.234\right)$, TC $\left(r_{\text {phi }}=0.056, P=1.000\right)$, and FC ( $\left.r_{\text {phi }}=0.064, P=0.453\right)$ was found. Likewise, no correlation between the presence of NTM and the number of AMB $\left(r_{\mathrm{pb}}=0.098, P=0.330\right)$, TC $\left(r_{\mathrm{pb}}=-0.024, P=\right.$ $0.812)$, and FC $\left(r_{\mathrm{pb}}=0.162, P=0.106\right)$ was observed. Of the 100 RTE-sprout samples analyzed, 12 yielded NTM. $M$. porcinum was the most frequently isolated organism (five isolates). We have also recovered two strains of M. abscessus, two of M. gordonae, two of M. mucogenicum, and one strain belonging to the M. avium complex (Table 2). Comparison of the number and species of NTM isolated from SPM and SVS showed no significant differences $(P=0.424)$. We also found no correlation between the presence of NTM and the presence of $\mathrm{AMB}, \mathrm{TC}$, and FC $\left(r_{\mathrm{phi}}=-0.081 ; P=0.475\right)$ in RTE-sprouts. Similarly, we did not observe correlation between the presence of NTM and the median concentration of TC $\left(r_{\mathrm{pb}}=0.046, P=0.653\right)$ and FC $\left(r_{\mathrm{pb}}=0.099, P=\right.$ $0.326)$. Nevertheless, we did observe a significant correlation between the presence of NTM and the median concentration of $\operatorname{AMB}\left(r_{\mathrm{pb}}=0.331 ; P=0.001\right)$.

\section{Discussion}

This study shows that AMB were detected in all RTE-salads regardless of source, with limits ranging from 3 to $6.6 \log _{10}$ $\mathrm{CFU} / \mathrm{g}$. AMB counts were found to be higher than those reported for RTE-salads in Johannesburg, South Africa [40]. In contrast, the number of these microorganisms (AMB) was found to be lower than that reported for RTE-salads from
Porto, Portugal, and Catalonia, Spain [41, 42]. The frequency of TC on RTE-salads observed here coincides with previous studies [43-45] carried out both in Mexico and in Brazil, countries where proper raw vegetable product handling and sanitation practices need to be promoted and implemented.

FC were identified in 32\% of RTE-salad samples; their frequency was substantially lower than that reported for RTE-salads from other developing countries. For instance, frequencies of $90.5 \%$ and $89 \%$ of FC were reported from Brazil [45] and Costa Rica [46], respectively. In spite of that, Gómez-Aldapa et al. [43] and Castro-Rosas et al. [44] reported frequencies of FC of $95.5 \%$ and $99 \%$, respectively, collected from restaurants in our country. We can assume that these higher numbers are the result of the greater number of people that can possibly be involved in the handling of this type of food in these types of places. Furthermore, these different numbers compared to the ones found by our work may be due also to the quality of water used for growing those vegetables, to the different methods of handling them, and to the different sampling techniques used. Unsatisfactory microbiological state of RTE-salads was more frequently observed in salads from SVS than in those from SPM $(P=0.001)$; we suggest that these SVS lack adequate appreciation of basic food safety issues; that is, street vendors keep the salads at room temperature (up to $27^{\circ} \mathrm{C}$ ) unlike supermarkets, where the salads are stored at refrigerated temperatures $\left(4\right.$ to $\left.7^{\circ} \mathrm{C}\right)$. Street vendors often use stands that are of inefficient construction; running water is not easily accessible and hand and dish washing are performed in the same bucket, sometimes without soap. Wastewater is usually discarded right there in the streets, and garbage is likewise "conveniently" discarded right next to the stands, providing 
attraction, food, and harborage for insects and rodents. In many cases, toilets are not available, thus forcing the vendors to eliminate their body wastes also in areas close by and to return to their vending sites without washing their hands. Such conditions and practices are likely to lead to cross contamination of street food. In other cases, vendors buy raw materials from dubious sources, and these materials may be contaminated with foodborne pathogens [47-49].

Regarding the microbiological quality of the sprouts collected in our work, the frequencies and concentrations of AMB found coincide with previous studies from different countries [3, 42, 50]. It has been reported that vegetable seeds could contain $<2 \log _{10} \mathrm{CFU} / \mathrm{g}$ of BMA. This naturally occurring population of microorganisms can rapidly increase during germination and sprouting because of the favorable conditions for bacterial growth [3]. Consequently, if seeds become contaminated with a pathogen, the sprouting process provides excellent conditions for consequent growth and distribution.

In our study, TC were detected in $100 \%$ of sprouts samples, result which coincides with that reported for bean sprouts in Central Mexico, where Salmonella and diarrheagenic Escherichia coli pathotypes were also identified [51]. On the other hand, FC were detected in the $69 \%$ of our RTE-sprout samples; this frequency was found to be lower than that reported for RTE-sprouts from markets in the town of Pachuca, Mexico [51].

Those high frequencies and concentrations of AMB, TC, and FC found in our RTE-sprouts may mean that they are so heavily contaminated that traditional sanitation practices would not be enough to reduce bacterial contamination. It has been suggested that an alternative, which can be used only by big food companies, for reducing the bacterial load in sprouts is the use of ionizing radiation, since it has been reported that a dose of 1.5 and $2 \mathrm{kGy}$ can significantly reduce E. coli O157:H7 and Salmonella to nondetectable limits in bean and radish sprouts [52]. Therefore, our results conclude, together with some others $[43,44,51]$ reported for our country, the highlighted need for implementing stricter hygienic control standards and measures for vegetables and sprouts grown in Mexico.

In this study, we combined conventional and molecular methods and detected and identified NTM in 7 RTE-salads and 12 RTE-sprouts. All NTM identified in this study have also been found in Mexican water samples [53] and in water samples from other countries $[21,54]$. Therefore, it is possible that water may be the original source of NTM transmission to vegetables (used in the salads) or sprouts while growing or during harvesting, washing, slicing, soaking, packaging, and preparation. NTM are opportunistic pathogens found in water and soil as normal flora. Therefore, another possibility of the presence of NTM in RTE-salads or RTE-sprouts comes from the soil and the water used for the growing and the irrigation, respectively, of those vegetables.

A significant correlation between the presence of NTM and the median concentration of $\operatorname{AMB}(P=0.001)$ was observed. This may be due to the fact that NTM as well as $\mathrm{AMB}$ are environmental organisms that have features in common, such as, growing in moderate to warm temperatures $\left(20\right.$ and $\left.45^{\circ} \mathrm{C}\right)$ and in aerobiosis conditions.

Some of the NTM identified in our study included species that have been frequently associated with human illness in other countries, that is, M. avium, M. fortuitum, M. abscessus, $M$. chelonae, and $M$. mucogenium $[55,56]$. In the case of $M$. avium, it has been suggested that the most common portals of entry of this microorganism are the gastrointestinal and the respiratory tracts $[57,58]$. In AIDS patients, M. avium is acquired predominantly via the gastrointestinal tract, where it is able to invade the intestinal mucosa, to infect and multiply within submucosal macrophages, and to cause bacteremia, leading to the dissemination of the microorganism to the liver, spleen, and bone marrow [58]. Regarding $M$. mucogenium, it has been associated with infection of the gastrointestinal tract in patients with a diagnosis of Crohn's disease [59].

In Mexico City, the prevalence of NTM infections is poorly known and only a few studies have been published. Among these studies, Lopez-Alvarez et al. [60] reported in 2010 that $15 \%$ of mycobacterial strains isolated from $67 \mathrm{HIV}$ patients belonged to NTM (10 strains were identified as $M$. avium and 1 strain was identified as $M$. intracellulare). In another recent study, Cortés-Torres et al. in 2013 [61] reported that $37 \%$ of 96 patients in a Mexico City Hospital, suffering from various immunodeficiencies, presented several strains of NTM, including M. avium, M. simiae, M. gordonae, and M. kansasii. Although no combined conclusion could be reached between these findings and ours, further studies of DNA fingerprinting of NTM should be carried out, in order to confirm that NTM isolated from RTE-salads and RTEsprouts are the same as those isolated from patients.

\section{Conclusions}

Most RTE-salads and RTE-sprouts analyzed in this study had unsatisfactory microbiological quality and some harbored NTM associated with illness. Measures to diminish or eliminate NTM strains from these food items might be advisable, such as a proper handling and washing before consumption of these products. RTE-salads and sprouts could be considered as potential sources for NTM infections in humans.

\section{Conflict of Interests}

The authors declare that there is no conflict of interests regarding the publication of this paper.

\section{Acknowledgments}

The authors would like to thank Dr. T. Horn-Copeland, M.D., for the helpful English language review of the paper. The study was supported by CONACyT, Mexico, Grant CB 2010156347-M (Jorge Alberto Gonzalez-y-Merchand), IPN SIP 20130531 and 20140732 (Jorge Francisco Cerna-Cortes), and IPN SIP 20140970 (Jorge Alberto Gonzalez-y-Merchand). Sandra Rivera-Gutierrez, Jorge Francisco Cerna-Cortes, and Jorge Alberto Gonzalez-y-Merchand are fellows of COFAA 
and EDI, IPN, and Elizabeth Fernandez-Rendon is fellow of COFAA and EDD, IPN.

\section{References}

[1] Food and Agriculture Organization and World Health Organization, Risk Assessment of Listeria monocytogenes in Ready-to-Eat Foods, Microbiological Risk Assessment Series 4, Interpretive Summary, 2004, http://apps.who.int/iris/bitstream/10665/42874/1/9241562617.pdf?ua $=1$.

[2] N. A. Almualla, L. C. Laleye, A. A. Abushelaibi, R. A. AlQassemi, A. A. Wasesa, and J. Baboucarr, "Aspects of the microbiological quality and safety of ready-to-eat foods in sharjah supermarkets in the United Arab Emirates," Journal of Food Protection, vol. 73, no. 7, pp. 1328-1331, 2010.

[3] S. D. Saroj, R. Shashidhar, V. Dhokane, S. Hajare, A. Sharma, and J. R. Bandekar, "Microbiological evaluation of sprouts marketed in Mumbai, India, and its suburbs," Journal of Food Protection, vol. 69 , no. 10, pp. 2515-2518, 2006.

[4] B. Mercanoglu Taban and A. K. Halkman, "Do leafy green vegetables and their ready-to-eat [RTE] salads carry a risk of foodborne pathogens?" Anaerobe, vol. 17, no. 6, pp. 286-287, 2011.

[5] G. Gu, J. Hu, J. M. Cevallos-Cevallos, S. M. Richardson, J. A. Bartz, and A. H. C. van Bruggen, "Internal colonization of Salmonella enterica serovar Typhimurium in tomato plants," PLoS ONE, vol. 6, no. 11, Article ID e27340, 2011.

[6] S. Kutter, A. Hartmann, and M. Schmid, "Colonization of barley (Hordeum vulgare) with Salmonella enterica and Listeria spp," FEMS Microbiology Ecology, vol. 56, no. 2, pp. 262-271, 2006.

[7] S. Pollack, "Consumer demand for fruit and vegetables: the U.S. example," 2001, http://www.ers.usda.gov/publications/wrs011/ wrs011h.pdf\#.VCppelfdldI.

[8] L. H. Gould, K. A. Walsh, A. R. Vieira et al., "Surveillance for foodborne disease outbreaks-United States, 1998-2008," MMWR Surveillance Summaries, vol. 62, no. 1, pp. 1-34, 2013.

[9] C. N. Berger, S. V. Sodha, R. K. Shaw et al., "Fresh fruit and vegetables as vehicles for the transmission of human pathogens," Environmental Microbiology, vol. 12, no. 9, pp. 2385-2397, 2010.

[10] M. F. Lynch, R. V. Tauxe, and C. W. Hedberg, "The growing burden of foodborne outbreaks due to contaminated fresh produce: Risks and opportunities," Epidemiology and Infection, vol. 137, no. 3, pp. 307-315, 2009.

[11] C. L. Little and I. A. Gillespie, "Prepared salads and public health," Journal of Applied Microbiology, vol. 105, no. 6, pp. 1729$1743,2008$.

[12] T. Lienemann, T. Niskanen, S. Guedes, A. Siitonen, M. Kuusi, and R. Rimhanen-Finne, "Iceberg lettuce as suggested source of a nationwide outbreak caused by two salmonella serotypes, newport and reading, in Finland in 2008," Journal of Food Protection, vol. 74, no. 6, pp. 1035-1040, 2011.

[13] K. Nygard, J. Lassen, L. Vold et al., "Outbreak of Salmonella Thompson infections linked to imported rucola lettuce," Foodborne Pathogens and Disease, vol. 5, no. 2, pp. 165-173, 2008.

[14] S. Werner, K. Boman, I. Einemo et al., "Outbreak of Salmonella Stanley in Sweden associated with alfalfa sprouts, July-August 2007," Euro Surveillance, vol. 12, no. 10, Article ID E071018.2, 2007.

[15] Y. T. H. P. van Duynhoven, M.-A. Widdowson, C. M. de Jager et al., "Salmonella enterica serotype Enteritidis phage type $4 \mathrm{~b}$ outbreak associated with bean sprouts," Emerging Infectious Diseases, vol. 8, no. 4, pp. 440-443, 2002.
[16] S. Ethelberg, M. Lisby, B. Bottiger et al., "Outbreaks of gastroenteritis linked to lettuce, Denmark, January 2010," Euro Surveillance, vol. 15, no. 6, 2010.

[17] I. Friesema, G. Sigmundsdottir, K. van der Zwaluw et al., "An international outbreak of Shiga toxin-producing Escherichia coli O157 infection due to lettuce, September-October 2007," Euro Surveillance, vol. 13, no. 50, 2008.

[18] A. Soderström, P. Osterberg, A. Lindqvist et al., "A large Escherichia coli O157 outbreak in Sweden associated with locally produced lettuce," Foodborne Pathogens and Disease, vol. 5, no. 3, pp. 339-349, 2008.

[19] U. Buchholz, H. Bernard, D. Werber et al., "German outbreak of Escherichia coli O104:H4 associated with sprouts," The New England Journal of Medicine, vol. 365, no. 19, pp. 1763-1770, 2011.

[20] O. Bezuidt, R. Pierneef, K. Mncube, G. Lima-Mendez, and O. N. Reva, "Mainstreams of horizontal gene exchange in enterobacteria: consideration of the outbreak of enterohemorrhagic E. coli O104:H4 in Germany in 2011," PLoS ONE, vol. 6, no. 10, Article ID e25702, 2011.

[21] J. O. Falkinham, "Impact of human activities on the ecology of nontuberculous mycobacteria," Future Microbiology, vol. 5, no. 6, pp. 951-960, 2010.

[22] J. O. Falkinham III, "Epidemiology of infection by nontuberculous mycobacteria," Clinical Microbiology Reviews, vol. 9, no. 2, pp. 177-215, 1996.

[23] B. A. Kendall and K. L. Winthrop, "Update on the epidemiology of pulmonary nontuberculous mycobacterial infections," Seminars in Respiratory and Critical Care Medicine, vol. 34, no. 1, pp. 87-94, 2013.

[24] C. Piersimoni and C. Scarparo, "Extrapulmonary infections associated with nontuberculous mycobacteria in immunocompetent persons," Emerging Infectious Diseases, vol. 15, no. 9, pp. 1351-1358, 2009.

[25] C. Piersimoni and C. Scarparo, "Pulmonary infections associated with non-tuberculous mycobacteria in immunocompetent patients," The Lancet Infectious Diseases, vol. 8, no. 5, pp. 323334, 2008.

[26] R. M. Thomson, J. G. Armstrong, and D. F. Looke, "Gastroesophageal reflux disease, acid suppression, and Mycobacterium avium complex pulmonary disease," Chest, vol. 131, no. 4, pp. 1166-1172, 2007.

[27] C. Argueta, S. Yoder, A. E. Holtzman et al., "Isolation and identification of nontuberculous mycobacteria from foods as possible exposure sources," Journal of Food Protection, vol. 63, no. 7, pp. 930-933, 2000.

[28] S. Yoder, C. Argueta, A. Holtzman et al., "PCR comparison of Mycobacterium avium isolates obtained from patients and foods," Applied and Environmental Microbiology, vol. 65, no. 6, pp. 2650-2653, 1999.

[29] C. F. von Reyn, R. D. Arbeit, A. N. A. Tosteson et al., "The international epidemiology of disseminated Mycobacterium avium complex infection in AIDS," AIDS, vol. 10, no. 9, pp. 10251032, 1996.

[30] U. S. Food and Drug Administration (FDA), "Bacteriological analytical manual online," 2013, http://www.fda.gov/Food/ FoodScienceResearch/LaboratoryMethods/ucm2006949.htm.

[31] "Norma oficial mexicana nom-093-ssal-1994, bienes y servicios. Practicas de higiene y sanidad en la preparacion de alimentos que se ofrecen en establecimientos fijos," 1995, http://conapesca.gob.mx/work/sites/cona/resources/LocalContent/8270/4/NOM093SSA11994.pdf. 
[32] L. Cobos-Marín, J. Montes-Vargas, S. Rivera-Gutierrez, A. Licea-Navarro, J. A. González-Y-Merchand, and I. EstradaGarcía, "A novel multiplex-PCR for the rapid identification of Mycobacterium bovis in clinical isolates of both veterinary and human origin," Epidemiology and Infection, vol. 130, no. 3, pp. 485-490, 2003.

[33] I. Perez-Martinez, A. Ponce-De-Leon, M. Bobadilla et al., "A novel identification scheme for genus Mycobacterium, $M$. tuberculosis complex, and seven mycobacteria species of human clinical impact," European Journal of Clinical Microbiology \& Infectious Diseases, vol. 27, no. 6, pp. 451-459, 2008.

[34] A. Telenti, F. Marchesi, M. Balz, F. Bally, E. C. Bottger, and T. Bodmer, "Rapid identification of mycobacteria to the species level by polymerase chain reaction and restriction enzyme analysis," Journal of Clinical Microbiology, vol. 31, no. 2, pp. 175178, 1993.

[35] P. Kirschner, B. Springer, U. Vogel et al., "Genotypic identification of mycobacteria by nucleic acid sequence determination: report of a 2-year experience in a clinical laboratory," Journal of Clinical Microbiology, vol. 31, no. 11, pp. 2882-2889, 1993.

[36] T. Adékambi, P. Colson, and M. Drancourt, "rpo B -based identification of nonpigmented and late-pigmenting rapidly growing mycobacteria," Journal of Clinical Microbiology, vol. 41, no. 12, pp. 5699-5708, 2003.

[37] "Identification of mycobacteria," PRA Database, http://app .chuv.ch/prasite/index.html.

[38] D. A. Relman, T. M. Schmidt, R. P. Macdermott, and S. Falkow, "Identification of the uncultured bacillus of Whipple's disease," New England Journal of Medicine, vol. 327, no. 5, pp. 293-301, 1992.

[39] "Guidelines for microbiological examination of ready-toeat foods," http://www.foodstandards.gov.au/publications/documents/Guidelines\%20for\%20Micro\%20exam.pdf.

[40] F. M. Mosupye and A. von Holy, "Microbiological quality and safety of ready-to-eat street-vended foods in Johannesburg, South Africa," Journal of Food Protection, vol. 62, no. 11, pp. 1278-1284, 1999.

[41] J. Campos, J. Mourão, N. Pestana, L. Peixe, C. Novais, and P. Antunes, "Microbiological quality of ready-to-eat salads: an underestimated vehicle of bacteria and clinically relevant antibiotic resistance genes," International Journal of Food Microbiology, vol. 166, no. 3, pp. 464-470, 2013.

[42] M. Abadias, J. Usall, M. Anguera, C. Solsona, and I. Viñas, "Microbiological quality of fresh, minimally-processed fruit and vegetables, and sprouts from retail establishments," International Journal of Food Microbiology, vol. 123, no. 1-2, pp. 121-129, 2008.

[43] C. A. Gómez-Aldapa, E. Rangel-Vargas, and J. Castro-Rosas, "Frequency and correlation of some enteric indicator bacteria and salmonella in ready-to-eat raw vegetable salads from Mexican restaurants," Journal of Food Science, vol. 78, no. 8, pp. M1201-M1207, 2013.

[44] J. Castro-Rosas, J. F. Cerna-Cortés, E. Méndez-Reyes, D. LopezHernandez, C. A. Gómez-Aldapa, and T. Estrada-Garcia, "Presence of faecal coliforms, Escherichia coli and diarrheagenic E. coli pathotypes in ready-to-eat salads, from an area where crops are irrigated with untreated sewage water," International Journal of Food Microbiology, vol. 156, no. 2, pp. 176-180, 2012.

[45] H. Fröder, C. G. Martins, K. L. O. De Souza, M. Landgraf, B. D. G. M. Franco, and M. T. Destro, "Minimally processed vegetable salads: microbial quality evaluation," Journal of Food Protection, vol. 70, no. 5, pp. 1277-1280, 2007.
[46] E. Rodríguez-Cavallini, C. Rodríguez, M. del Mar Gamboa, and M. L. Arias, "Microbiological evaluation of ready-to-eat foods manufactured by small Costa Rican industries," Archivos Latinoamericanos de Nutricion, vol. 60, no. 2, pp. 179-183, 2010.

[47] S. Rane, "Street vended food in developing world: hazard analyses," Indian Journal of Microbiology, vol. 51, no. 1, pp. 100106, 2011.

[48] D. H. Tambekar, V. J. Jaiswal, D. V. Dhanorkar, P. B. Gulhane, and M. N. Dudhane, "Identification of microbiological hazards and safety of ready-to-eat food vended in streets of Amravati City, India," Journal of Applied Biosciences, vol. 7, pp. 195-201, 2008.

[49] E. O. Ekanem, "The street food trade in Africa: safety and socioenvironmental issues," Food Control, vol. 9, no. 4, pp. 211-215, 1998.

[50] D. Althaus, E. Hofer, S. Corti, A. Julmi, and R. Stephan, "Bacteriological survey of ready-to-eat lettuce, fresh-cut fruit, and sprouts collected from the swiss market," Journal of Food Protection, vol. 75, no. 7, pp. 1338-1341, 2012.

[51] J. F. Cerna-Cortes, C. A. Gómez-Aldapa, E. Rangel-Vargas, E. Ramírez-Cruz, and J. Castro-Rosas, "Presence of indicator bacteria, Salmonella and diarrheagenic Escherichia coli pathotypes on mung bean sprouts from public markets in Pachuca, Mexico," Food Control, vol. 31, no. 2, pp. 280-283, 2013.

[52] M. L. Bari, M. I. Al-Haq, T. Kawasaki et al., "Irradiation to kill Escherichia coli O157:H7 and Salmonella on ready-to-eat radish and mung bean sprouts," Journal of Food Protection, vol. 67, no. 10, pp. 2263-2268, 2004.

[53] I. Perez-Martinez, D. A. Aguilar-Ayala, E. Fernandez-Rendon et al., "Occurrence of potentially pathogenic nontuberculous mycobacteria in Mexican household potable water: a pilot study," BMC Research Notes, vol. 6, no. 1, article 531, 2013.

[54] R. M. Thomson, R. Carter, C. Tolson, C. Coulter, F. Huygens, and M. Hargreaves, "Factors associated with the isolation of Nontuberculous mycobacteria (NTM) from a large municipal water system in Brisbane, Australia," BMC Microbiology, vol. 13, no. 1 , article 89, 2013.

[55] A. R. F. da Costa, J. O. Falkinham III, M. L. Lopes et al., "Occurrence of nontuberculous mycobacterial pulmonary infection in an endemic area of tuberculosis," PLoS Neglected Tropical Diseases, vol. 7, no. 7, Article ID e2340, 2013.

[56] P. M. Cassidy, K. Hedberg, A. Saulson, E. McNelly, and K. L. Winthrop, "Nontuberculous mycobacterial disease prevalence and risk factors: a changing epidemiology," Clinical Infectious Diseases, vol. 49, no. 12, pp. el24-e129, 2009.

[57] C. A. Benson, "Disease due to the Mycobacterium avium complex in patients with AIDS: epidemiology and clinical syndrome," Clinical Infectious Diseases, vol. 18, supplement 3, pp. S218-S222, 1994.

[58] B. Damsker and E. J. Bottone, "Mycobacterium aviumMycobacterium intracellulare from the intestinal tracts of patients with the acquired immunodeficiency syndrome: concepts regarding acquisition and pathogenesis," Journal of Infectious Diseases, vol. 151, no. 1, pp. 179-181, 1985.

[59] C. Y. Tzen and T. Y. Wu, "Detection of mycobacteria in Crohn's disease by a broad spectrum polymerase chain reaction," Journal of the Formosan Medical Association, vol. 105, no. 4, pp. 290 298, 2006.

[60] R. Lopez-Alvarez, C. Badillo-Lopez, J. F. Cerna-Cortes et al., "First insights into the genetic diversity of Mycobacterium tuberculosis isolates from HIV-infected Mexican patients and 
mutations causing multidrug resistance," BMC Microbiology, vol. 10, article 82, 2010.

[61] N. Cortés-Torres, J. A. González-y-Merchand, C. GonzálezBonilla, and G. García-Elorriaga, "Molecular analysis of mycobacteria isolated in Mexican patients with different immunodeficiencies in a tertiary care hospital," Archives of Medical Research, vol. 44, no. 7, pp. 562-569, 2013. 

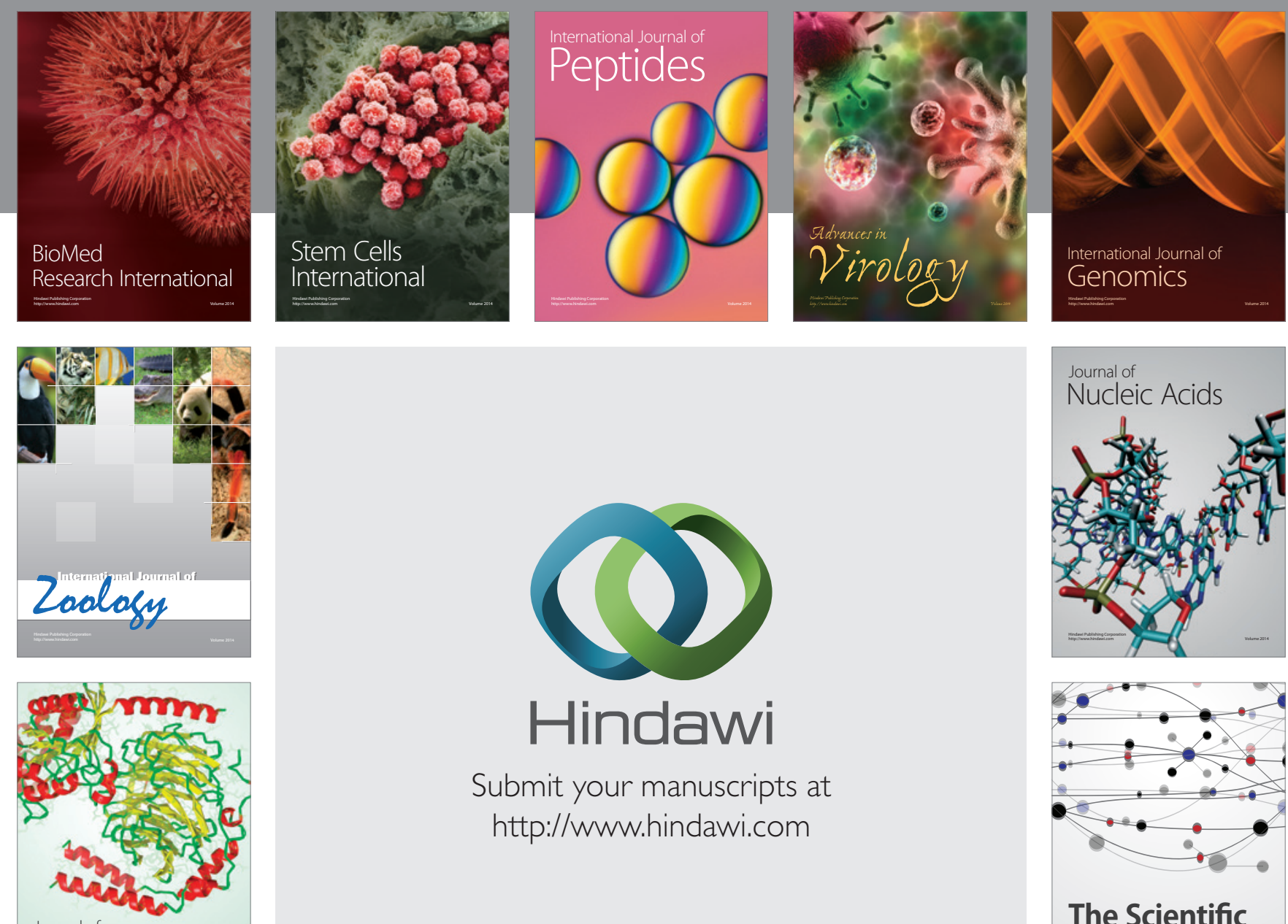

Submit your manuscripts at

http://www.hindawi.com

Journal of
Signal Transduction
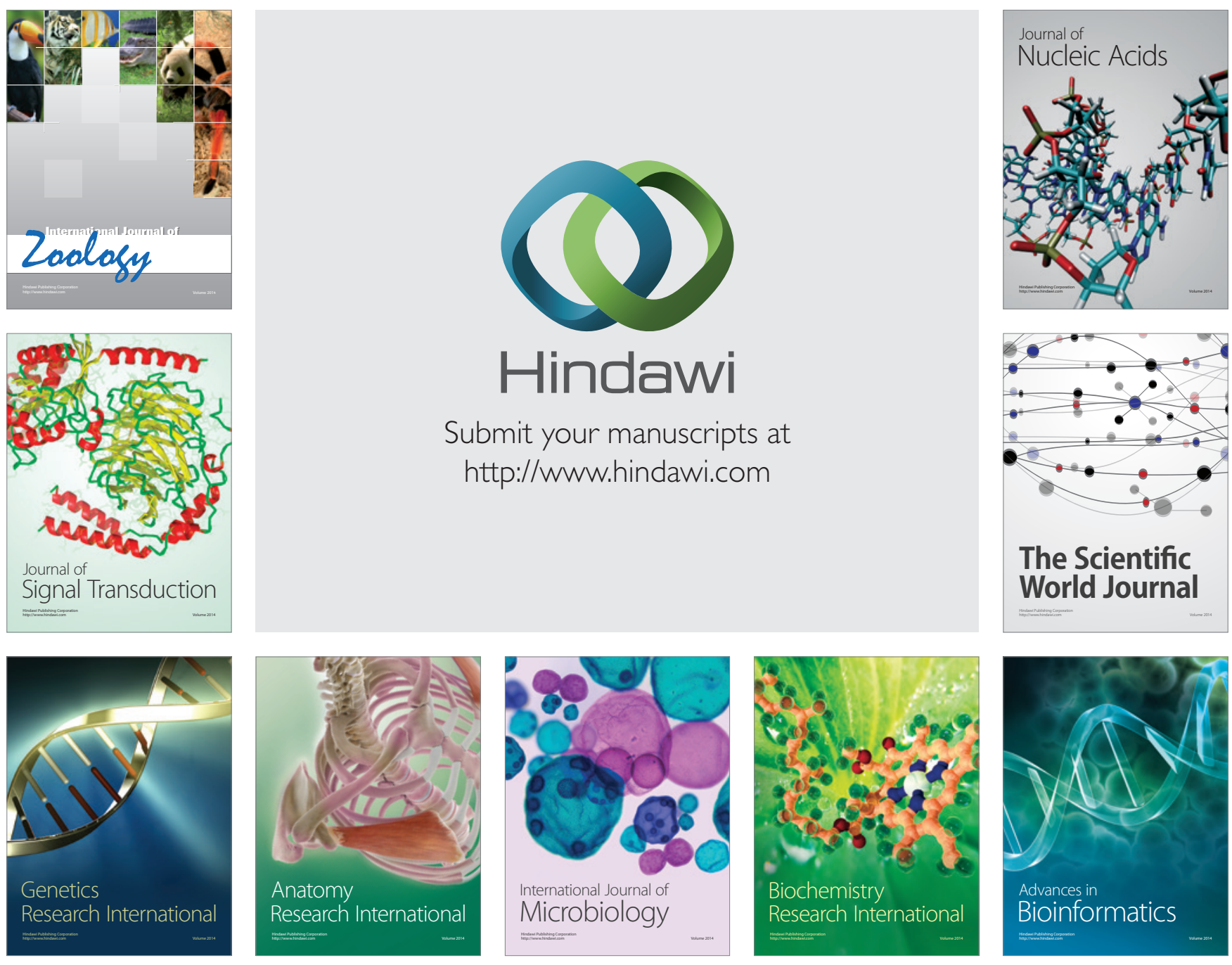

The Scientific World Journal
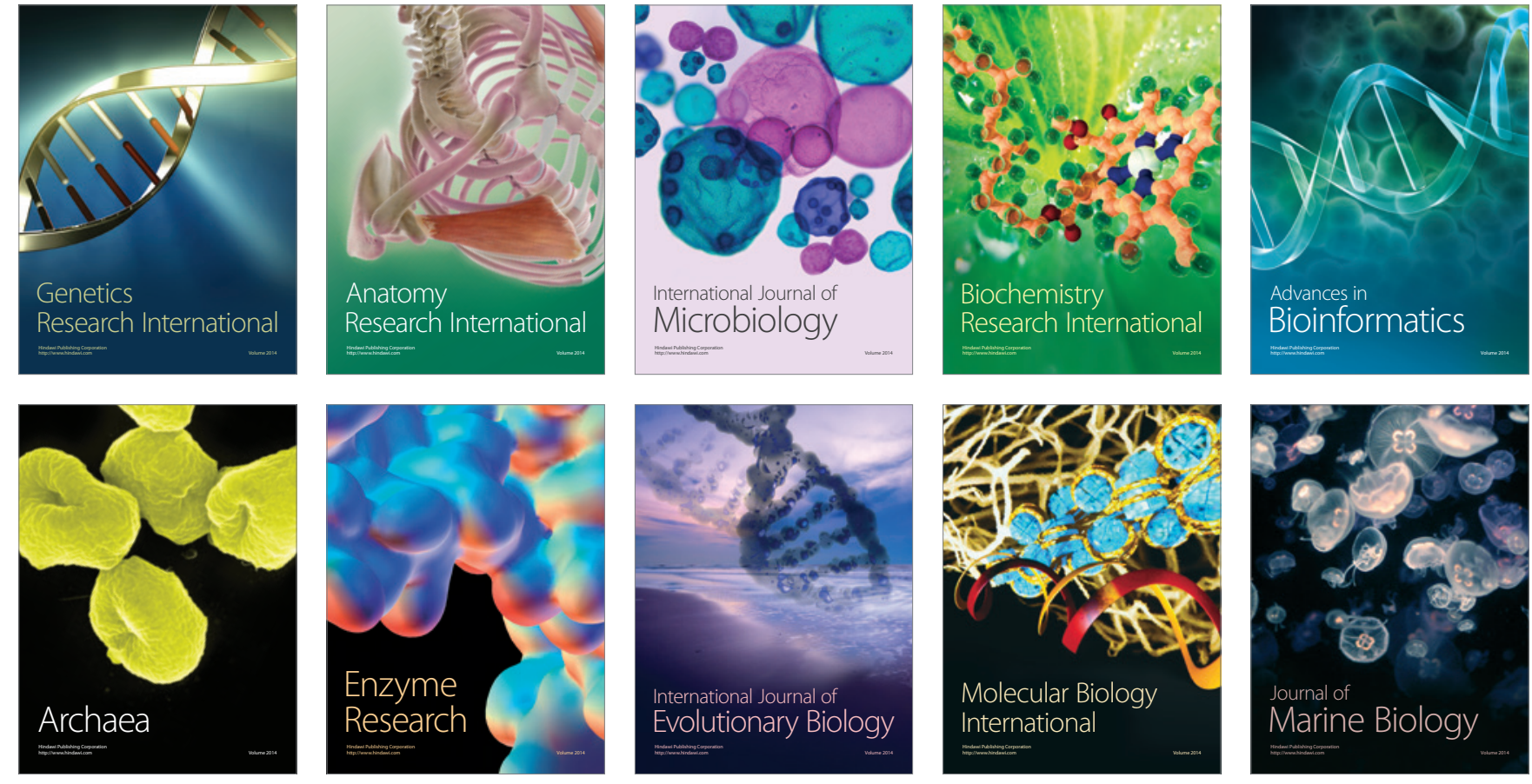